\title{
Identify the Imprints of Taoism in Vietnam's Ancient Literature
}

\author{
Vu Hong Van* \\ University of Transport and Communications, Hanoi, Vietnam
}

\begin{abstract}
*Corresponding Author: Vu Hong Van, University of Transport and Communications, Hanoi, Vietnam
\end{abstract}
\begin{abstract}
Historically, Vietnam has interacted with many religions in the world. Many world religions when penetrating into Vietnam have been received by Vietnamese people, adapted to the local culture. One of the religions that entered Vietnam quite early was Taoism. Taoism is an ancient religion, long-lasting in Chinese history, it has overcome many challenges of space and time to survive today. Right after its birth, Taoism had a certain influence from Sichuan, Ha Dong and spread to the Changjiangbasin and spread throughout the vast Chinese country. Historically, Taoism has also interacted with many different cultures and left its mark in many East Asian countries. We can see its influence in the beliefs, religions and rituals of many classes of people, in many countries, over the centuries.

During the first propagation into Vietnam, Taoism found similar long - standing beliefs available. The cult of magic, witchcraft, talisman ... of the ancient Vietnamese, has become a fertile ground for sowing Taoist seeds. Taoism has a great influence on the spiritual life of Vietnamese people, including literature. On the basis of researching the documents and articles going on to study the influence of Taoism on Vietnam's ancient literature, thereby contributing to understanding the process of exchange and acculturation of Vietnamese people in history.
\end{abstract}

Keywords: Identify, imprints, Taoism, Vietnam, Ancient, Literature

\section{INTRODUCTION}

Since the beginning of the BC, Vietnam has started to separate from the Southeast Asian cultural region, entering the trajectory of East Asian culture, or the cultural area influenced by China, "Cultural region Chinese characters" (Kanji bunkaken) together with Korea - South Korea and Japan. Understanding this cultural region, we saw that the literature of countries has strange steps. The similarity was due to similar social-historical issues and by being strongly influenced by Chinese.

The Vietnamese people have been available in the spirit of art since the past. With funny naive imaginations, with a rudimentary level of knowledge, they know how to put lyrics and stories as well as set stories. Without words, they circulated works by mouth. It was not until later, although the writing appeared and changed many times, but because most people in general were less able to study the old stories, new stories were mostly from mouth to mouth another but left.

Like other ethnic groups, the ancient Vietnamese also had mythical art. The Vietnamese myths are simple but interesting and interesting. This is a national literary tradition, a document about the oldest period of Vietnamese life. It is the source of our history and story later. Following the myth, Vietnamese people still keep writing. From colorful mythical myths, proceed to build athletic heroes, stories of humanity, but have been sanctified. What is especially in Vietnam, polytheism has existed since ancient times still remains ruins until later. Thanks to that, we can easily learn the origin of some legends and legends.

In the Northern domination period, there were the colonists who recorded some ancient stories of Vietnamese people, such as the book Giao Chau signed by Trieu Cong and Tang Sang, Luu Tuan's book of Manneral expressions in the Tang Dynasty (Dai Viet Su KyToanthu, 2004). They recorded a few stories, due to curiosity rather than intention to collect. But it also proves that our ancestors' old stories have been noticed by foreigners while learning about Vietnamese and Vietnamese soil.

In the Ly and Tran dynasties, feudal writers began collecting myths, myths and fairy tales of the nation. It should be noted that all types of ancient stories, whether oral or recorded, of folk or of the dominant ruling class, are not included in the literary class by the majority of the feudal class. 
Although they did not consider it bullshit, they did not show any serious expression. In education and in the faculty, people speak only of the poet without teaching to the "story" whether it is a novel or a fairy. The scholar who writes for the sake of collecting fairy tales and national myths is for the purpose of finding additional documents for the national history rather than for preserving folklore.

In the process of communicating with the ideologies in the world that have been spread into Vietnam, Vietnamese people have been selectively acquired and modified to suit Vietnamese people's minds. One of the ideologies spread into Vietnam very early (about the 2nd century) is Taoism. As Tran Van Giau once said:

"Perhaps because the rural commune of Vietnam is slowly dissolved and its relic is too long to exist, so the original thought of the magic belief dissipates very slowly, but other religions or thoughts from the outside that have been imported into our country are also more or less tolerated. Taoism enters Vietnam and meets that same similarities of magic so it is easy to receive" (Giau. T. V., 1973, p.446). "It was like a familiar piece of land, the people who did not learn were good”(Giau. T. V., 1973, p.447).

Or as Tran Ngoc Them, once said:

"In the first time spreading to our country, Taoism found similar long-standing beliefs. The cult of magic, witchcraft, talismans ... of people Ancient Viet, became a fertile ground for cultivating Taoism, so it is easy to understand why Taoism, first of all, was a witchcraft, quickly penetrated and merged easily with beliefs. Ancient magic to the point where there is no boundary" (Them. T. N., 2000, p. 277).

\section{SOMETHING ABOUT TAOISM AND TYPICAL IMAGES OF TAOISM}

"Taoism is an important constituent of the traditional Chinese culture and has a great influence on every social aspect and ancient cultural and artistic thoughts in China" (History of Chinese Culture, 1999, p. 924).

"The Taoism is a religion that grows on Chinese soil. It is not the same as the other three major religions in the world, Buddhism, Ixlamism and Christianity, because these religions have clear doctrines and basic scriptures, and Taoism is not. The cult of Taoism Lao Tzu, a typical scholar of the Tien Qin Dynasty, was the patriarch, but in fact, Lao Tzu was added by the next generation, and he himself never propagated the religion" (History of Chinese Culture, 1999, p. 902).

So far, it is very difficult to define clearly source of Taoism. The Taoism was often identified with the Taoist which was a school of thought of the Tien Qin period with the philosophies of Lao Tzu, LengZi, Chuang Tzu ... But Taoism was not entirely a cult that acts like Taoists of Tien Qin period, instead of the later Taoists combined with the Way of method to immortality, magic and folk beliefs of Chinese to form Taoism.

The Taoism was a polytheistic religion, worshiped gods were very complicated. Ever since the establishment of religion, Taoism worshiped Lao Tzu as the supreme deity, the later stages of development, Taoism added Theravada Thien Ton. Then the position of the Theravada Thien Ton was higher than Lao Tzu. In the later stages of development, Taoism called Theravada Thien Ton was Ngoc Thanh, called Lao Tzu was Thai Thanh. In addition, Taoism also added Thuong Thanh Linh BaoThien Ton. All three supreme gods were called Tam Thanh.Through the subsequent development of Taoism, the gods were continuously supplemented, forming an extremely diverse and rich fairies system. That was also the basic characteristic of Taoism. The view of the elves was also the strongest factor that deeply affected to the ancient Chinese novels of Vietnam.

In Vietnam in particular and in East Asia in general, Taoism had a great impact on all fields of life, especially in spiritual activities. In traditional point of view, Taoism was introduced inVietnam very early ${ }^{1}$ without any obstacles. It developed freely, dominated people's spiritual activities and developed from a low level to a high level.

\footnotetext{
${ }^{1}$ Currently, there has not been any confirmation of the time when Taoism was introduced into Vietnam. But according to some historical data, some remnants of history and some stories in Vietnam, it is possible that Taoism was spread into Vietnam around the end of the 2nd century.
} 
When identifying the elements of Taoism in ancient Vietnamese literature, we need to recognize the following basic characteristics:

Firstly, religions in general think that "life is suffering", full of suffering, there was nothing to be attached to. They hoped for a happy life in another realm, another world, or into a fanciful paradise, desired after death of a saved soul. And Taoism thought that living in life was a joyful thing, death was suffering. The doctrine of Taoism was that of birth, optimism, and encouragement of people to cultivate in order to prolong their life, the supreme ideal was "immortal life", which is the first, wants nothing. Commenting on the book "Storm of the Deathly Hallows", a book on General History of Chinese Culture, edited by Ngo VinhChinh, VuongQuy Mien wrote: "If you drink half a needle, your immortality will be immortal, harm cannot be hurt. It is possible to raise wife and children, keep officials to do what they want, no one can stop them" (Chinh. N. V. \& Mien. V. Q., 1994, p. 92). Therefore, Taoism absorbed the traditional nurturing technique and added the religious type explanation that developed it according to the mystical tendency.

Secondly, religions generally separate two separate worlds: the real world and the "surreal" world, they despise this world. The fairytale world of Taoism was not the same as the real world but was not completely separate. According to the conception of Taoism, after cultivating the first path, it was still possible to go back to the real world, even if there is resentment in the earthly life, then it may return to grace or revenge, defend righteousness, eliminating evil, then the boundary between humanity and wonder is removed. This shows that, in addition to the idea of the Taoism, it also implied a policy of entry.

Third, all religions are often spiritually, worshiping a supreme being, and Taoism was a polytheistic religion. Taoism divides the world into two: heaven and people, dividing gods into many types. Taoism not only believed that all things in the universe had gods but even parts of the human body have divine control. In a certain way, Taoism had a thought to promote human power. The natural, social, and human worlds are unitary, of the same origin, with the same structure and sharing with each other. If people know how to develop the power of gods in the body, then humans could make the whole god follow his will. If man pursued the practice of cultivation and cultivation, he could become an immortal and immortal.

Fourth, since there was a lack of consistency in sects and scriptures from the beginning, the fairy system, the name of the gods, also had some differences. However, the image of Tam Thanh trio was relatively consistent (although it has many different names). The precepts of the sects are relatively complicated, more or less depending on the clergy and the clergy's level. Therefore, Taoism had many different precepts.

\section{AbOUT The VietnaM's AnCIENT Literature}

The Vietnam's ancient literature was a kind of prose created by human imagination. Ancient Chinese novels were the compositions of ancient people written by Chinese characters. According to initial statistics, there were about forty Chinese ancient novels that exist today. The content of the novels revolves around the following issues:

The pen-fiction novel, also known as the "loyal" novel, consists of short stories, "writings, troubles" related to national heroes, historical and cultural celebrities recorded mainly not by "pen damage" but by "pen credit". Even the part that we now see is "pen damage" was also the ancient author conceived as "real" and "real" that is to see how to write so, listen to copy, not add, not reduce.

Monstrous novels: including horror stories, unlike reality about people, things, and gods ... recorded according to the author's perception, but in fact, in this kind, we had seen fictional writing still occupying the part a lot of.

Legendary novels: "tradition" or "curious", meaning the intention to write to satisfy the curiosity of the reader. This type of novel was born and developed on the basis of monstrous novels, but different from the monstrous novels in that the author used the fictional writing in a completely active and conscious way. If the main job of monstrous novels was to write, in order to save a life of a strange idea the advice, the main task of the Legendary novels d was "indite", borrowing a rare stories to convey the writer's mind. 
Taoism also greatly affected Vietnamese ancient novels, especially novels written in Chinese. It was easy to see the imprint of Taoism through many novels written in Chinese, namely:

Viet Dien U Linh (Collection of Stories on the Shady and Spiritual World of the Viet Realm) with the stories: Uyminh dung liethientrungta thanhPhuHuudaivuong (Ly Hoang), Thai uytrungtue Vu Luong Cong (Muc Than), Ung thienhoaducnguyentrunghauthodiaKy Nguyen Quan, QuangLoithanhhuuuytePhu Ung daivuong (Than Long Do), MinhchulinhungchieucamBaoHuudaivuong(Mountain God of DongCo),Tan Vienhuuthanhkhuongquoc Hien Ung daivuong (Son Tinh), ThienholinhungChuong Vuquoccong, Loitelinhthong Hue Tin daivuong (Nam Hai Long VuongQuan), etc.

Linh Nam Chich Quai(Selection of Strange Tales in Linh Nam) with the stories: Ngutinhtruyen (The Tale ofNgutinh), Ho tinhtruyen (The Tale of Ho tinh), Moctinhtruyen (The Tale of Moctinh), Nhat Da Trach truyen (The Tale of Nhat Da Trach), Dong ThienVuongtruyen (The Tale of Dong ThienVuong), Ly Ong Trongtruyen (The Tale of Ly Ong Trong), Tan VienTruyen (The tale of Tan Vien),Man Nuongtruyen (The tale of Man Nuong), etc.

Thanh Tong Di Thao(Thanh Tong's Posthumous Manuscript) with two volumes: the upper volume and the lower volume. The upper volume included: Chau Maiyeunu truyen (The story of ogress Chau Mai), Thiemthumieudue ky (The article of a toad descent), Luong Phat DauThuyetKy(The article of two Buddhists arguing), Phucaitruyen (The story of a rich beggar), Nhithan nu truyen (The Story of two goddesses), Son quanpha (The genealogy of the mountain god), Giaothuluc (The letter of a mosquito), Hoaquockyduyen (A strange Fate in China), Vu mon tungmieu(The laughter at Vu Mon mountain), Ngugiachi di (The strange story of afisherman's family);

The lower volume included: Duong phutruyen (The story of the goat husband), Tran nhancuthuyphu (Earthly People in the palace of the River God), Lang Bac phungtien (Meeting a god at Lang Bac Lake), MongKy (The story about a dream), Thu tinhtruyen (The story of a ghost mouse), Nhatthuthuthan $n u$ (Getting married to a goddess thanks to an inscription).

TruyenKy Man Luc (Collection of Strange Tales) with the stories: Tra Dong giangdanluc (The story of a mandarin reborn), Long Dinhdoitung (Argument in Long Dinh), TuThuctienhon luc (TuThuc married afairy), Pham Tu Hu du thientaoluc (The story of Pham Tu Hu going to heaven), Na Sinhtieudoiluc (The talk of the woodcutter at Na Mountain), etc.

TruyenKy Tan Pha (New genealogy of fantasy short stories)with the stories: Van Cat than nu (Goddess Van Cat), An Aplietnu (The Heroine in An Ap), BichCaukyngo (A strange meeting in BichCau), Hoanh Son tiencuc (A fairy game of chess on Hoanh Son Mountain), etc.

In addition, there were a number of authors such as Nguyen BinhKhiem, PhungKhacKhoan, Nguyen DinhChieu ... They were originally Confucian people who had patriotic love but were dissatisfied with the time so retreat In hiding, take wine bottles, poetry bags as friends. Since then, the "idle", "innocent", "pure" rewards ... of Taoism have profoundly affected my writing of poetry.

Through these ancient literary works, it could be seen that not only in China but even in Vietnam "... many fairy images and legends in Taoism were the sources for ancient literary works". (Hanoi National University of Education, Center for Chinese Studies, 2000, p. 314)

\section{THE IMPRINTS OF TAOISM IN VIETNAM's ANCIENT LITERATURE}

It can be said that Taoism affected the imagination of writers who were on their ways to find new values in human life, making people become more and more perfect and enjoy more literary sense of beauty. Taoism contributed to leading ancient novels of our country from But ky, Chichquai, Truyenky and to some other genres such as diem tinh, cong an. The influence of Taoism on Vietnamese ancient novels can be determined on the following basic issues:

In terms of environment (context) and time: According to Taoism, the activities of humans, fairies and ghosts were divided into three different spaces: The upper space was for fairies; the middle space was for humans; and the lower space was for ghosts. "All things in heaven and earth cannot be determined, just follow the heart to think. In life and death, there are three parts related to each other: fairies above, humans in the middle, and devils below. Good people become fairies. Fairies are degraded to become humans. Wicked people become devils. Devils do good things and become 
people again. Devils imitate people; people imitate fairies - around and around. That is a small difference between the death and life" (Hanoi National University of Education, Center for Chinese Studies 2000, 314).In TruyenKy Man Luc, there was a similar idea."Now I tell you: in the transmigration of heaven and earth, there are only two species of good and evil. For people who regularly do good things, their names will have been recorded in heaven even when they are still alive. For people who do evil things, their names have been recorded in hell even when they have not died" (Hanoi National University of Education, Center for Chinese Studies, 2000, p. 314).

According to Taoism, the fairyland consisted of thirty-six floors of heaven, ten continents and three islands. In which, there were ten large fairy caves, thirty-six small fairy caves and seventy-two lands of happiness. The fairy caves were on the mainland and the fairy islands were in the sea. Although these were the products of the Taoists' imagination, which were not true, but they provided Vietnamese authors with materials to write novels, especially truyenky, trichquai. Many novels praised the beauty as well as the leisurely and comfortable lives of the fairyland. For example, in TuThuctien hon luc (TuThuc married a fairy), the author praised the fairy scene: "Trying to climb up,the cave became wider and wider. When he was at the top of the mountain, the sky was bright. Looking around, he saw magnificent castles with green and red clouds on the rails and strange flowers blooming in front of the doors. He thought if it was not a place for worship, it must be an area forpeople who stayed away from the world, like Thuumountain and Dao spring ${ }^{2}$, for example" (see Nguyen $\mathrm{Du}, 1943)$. In addition to praising the beauty of the fairyland, in TuThuctien hon luc, TuThuc met Giang Huong, whose amazing beauty made him infatuated. In the splendid scenery of the fairyland, everything seemed to completely vanish, leaving only the extreme happiness between TuThuc and Giang Huong.

The time in Vietnamese ancient novels was sometimes unreal and was only the time in the each person's mind. In terms of this, Vietnamese ancient novels were also greatly influenced by Taoism. In Taoism's point of view, one year in heaven equaled 100 years on earth. This view point can be seen in TuThuctienhon luc (TuThuc married a fairy): TuThuc lived in heaven for a year, but when he returned to the earth, he realized that everything had changed and he no longer recognized his old acquaintances. He used his name to ask the elders in the village and someone said: "When I was young, I was told that my great-grandfather, with the same name as yours, went to the mountains for over 80 years now. This year was the 5th year under the reign of DienNinh, the third generation of Le dynasty, but he had not returned"(Nguyen Du 1943, p. 98 - 99). Thus, in the conception of Vietnamese ancient novels, one year in heaven equaled about 100 years on earth. However, this was only the time that humans estimated and interpreted to be in accordance with the heaven and earth.

In Vietnamese ancient novels, the space and time were sometimes ignored. This can be shown in BichCaukyngo (Truyenky tan pha): "That afternoon, there was a wine party in the yard with all kinds of fruit. GiangKieugot dressed neatly and watched the moon with TuUyen. Suddenly, through the partition, they saw that the castle was like pearls with bright red almonds. The scenery was different from any other places on earth. There were yellow apricot blossoms and purple plums; everything was beautiful like in heaven. After a while, Princess Tien Dung and Giang Huong came down from the clouds. Other fairies came down later -more than a hundred fairies in total" (Diem, D. T., 1962, p. 118).In Vietnamese legends, Princess Tien Dung was in the Hung Vuong dynasty; Giang Huong was in the Tran dynasty and GiangKieu - TuUyen were in the the Le dynasty, but they could overcome space and time to be able to meet one another. This was really a new creation, creating a thrill for Vietnamese ancient novels.

For the construction of characters in ancient novels in Chinese, we also recognized the influence of Taoism. One of the main directions of Taoism was to practise to become gods and seek for immortality. Taoism formed a system of practising methods in order to prolong the life-span and

\footnotetext{
${ }^{2}$ Thuumountain: In the past, the Western region had the Thuu Linh mountain, because the mountain of the Thuu bird should be named. Source of Dao: According to Dao Nguyen's original flower, Dao had a fisherman in Vu Lang who went to the forest to get lost. There the fishermen met a very peaceful hamlet, asking if they were refugees of the Qin Dynasty, they did not know anything about the present time. Some fishermen had left for several days. The story came to the county official, he wanted the fisherman to take it, but when he returned, the fisherman could not find any trace. From then on, the words of Vu Lang, source Dao, and Dao village just pointed to a secluded place and also a fairyland.
} 
prevent diseases and accidents so that people could live long whereas their bodies remained young forever. The Taoist gods could call for wind and rain and could travel like clouds and smoke. They could ride a cloud or a dragon to heaven and fly over famous mountains. They didn't eat cereals and just breathed the air to live. Some people could make themselves invisible so that nobody could see them. Thus, the Taoist gods had two basic characteristics: First, they were immortal. Secondly, they had magical powers. These two characteristics were demonstrated through two types of images: deifying earthly humans and making gods become earthly humans.

Le Thanh Tong (King), the Confucian saint, tends to be closer to the gods than the kings before him. Thanh Tong Di Thao (Thanh Tong's Posthumous Manuscript), the work of legend is Le Thanh Tong's records of bizarre, spooky stories showing the king's interest in the gods. In the story of see Fairy at Dam Dam Lake, Le Thanh Tong (King) made clear the vision of the influence of the Prophet through the prophet's dialogue:

"Behold, the tower is high and gold, and the road is full, and when it comes to it, it rattles bells and feathers, and the dragon's floor holds the power of heaven. But compared to the rattan car, the horse cranes, the morning catch the sun and the sun, the afternoon looks cloudy mountain in Vu Giap is more liberal? The sea-flavored sea food is fully awake in the four seas, roaming the ground, everyone is satisfied with one person and more. But compared to the wine of the Quynh ${ }^{3}$, eating the essence of all kinds of plants, also the three thousand years of peach table, three thousand years of results, which is more precious? The mountain is stunted, I own him, clean land in the stream, we make a place, the places where the fields of the phoenix, the river of flamboyant in the sky, have my footprints going on. If compared to the destiny from heaven, reigning is limited, everyone who is narrow, clearly see it. If the lotus leaf is used as a shirt, sheath of Cau tree fall down as a sun hat. Thousands of poems soaked in books, in tiger forests do not worry, alcohol quips a gourd, crossed the three peaches are not afraid. Soak moon singing wind, dragon body phoenix spirit, old renewal, instead of a long-term sales place. Behold, those who are crushed, one day, four realms or stubborn places, one who is not grateful, the sky has not yet been dressed, the ball to lunch is eaten, disguised to travel, throughout unfinished days, only old and old worries. So whoever is busy with the house is very clear. Being an idle day, even if you take the throne, you will not be able to change it, if only you are with the prince, let alone be given the right" (Thanh Tong's Posthumous Manuscript, 2016, p. 55).

In a poem of the cave of Ho Cong, a place where the legend of a Taoist monk is kept, Le Thanh Tong also expressed the unconscious thought of influencing Taoism:

"Life is a dream like a dream.

The gospel fairy is extremely delightful"

(Thanh Tong's Posthumous Manuscript, 2016, p. 84)

In Vietnamese ancient novels, gods becoming earthly humans included Giang Huong in TuThuctien hon luc, $\mathrm{Nu}$ Than in Nhatthuthu than $n u$, QuynhNuong inVan Cat than nu, GiangKieu in BichCaukyngoin Truyenky tan pha of Doan Thi Diem, etc. All of them had fairy origins, had supernatural magic and could ride clouds, cross the sea, and transform into many other people. They sometimes transformed into beautiful girls teasing earthly people; they sometimes turned into an old ladies or old beggars standing on the sidewalk. GiangKieuhid herself a painting and prepared meals for TuUyen every day. Due to various reasons, they came down to earth to become secular people. They also got married, gave birth to children and had enough "seven human feelings - six human passions" like normal people. All those characters "from GiangKieu, Princess Lieu - Hanh, Lady Dinh to TuUyen were all mysterious. The images of Princess Lieu Hanh, GiangKieutransforming themselves, Tu - Uyen riding cranes to heaven showed the profound manner of Taoism" (Diem, D. T., 1962, p. 12).

In terms of humans becoming gods, there were a Taoistsur named La in Nam Ong Mong Luc, Chu Dong Tu and Tien Dung in Linh Nam Chich Quai-Nhat Da Trach, TuThuc in Truyenky man luc TuThuc Tien hon luc, Chu Sinh in Thanh Tong di thao - Hoa Quoc kyduyen,the girl in Thanh Khevillage in Thanh Tong di thao - Duong phutruyen, and so on. Each of these specific characters had

${ }^{3}$ Quynh is a flower blooming at night 
earthly origins, experiencing many difficulties and challenges and becoming gods or goddesses thanks to their honesty and contribution to life.

Some characters in Vietnamese ancient novels also expressed the conception of birth and death in Taoism. For example, the God playing the flute that Le Thanh Tong metat Lang Bac Lake in Thanh Tong di thao, Lang Bac phungtien (Meeting a God at Lang Bac Lake) or the practising woman at VongNguyetcommunal temple, Tam Dao Mountain in Dao hoamongky overcame the birth and death of their bodies and souls. They lived thousands of years, often riding clouds and wind and suddenly disappearing or appearing.

The idle and reclusive thought also greatly influenced the ancient literary works of Vietnam, especially in the XV - XVI century. The deeper Taoist influence was Nguyen BinhKhiem. The concept of the human universe of Nguyen BinhKhiem, although it was derived from "dịchlý" but we still see there was the influence of Taoist thought. He often mentions in his poetry the philosophical thesis of mutuality, mutuality, blessings based on each other - a way of dealing with Taoism:

\section{"Flowers show off blooming so rotten,}

The water is filled with water".

(BạchVânquốcngữthi, chapter 52)

A famous student of Nguyen BinhKhiem was PhungKhacKhoan. He was a positively prominent grape house, wholeheartedly helping Le Trung Hung's house. When he was old, he often traveled here and there, visiting interesting places and enjoying friends with wine bags. However, the poem was influenced by Taoism, was done when he was imprisoned in the South when he was young, including: Dao Nguyen Hanh, NguPhuNhap Dao Nguyen, Lam Tuyen Van... beginning the sentences:

"Unconscious is a fairy god,

Consider whether the forest animal scene is fun? "

(Hung. N. P., 2001, p. 215)

The historical context of Vietnamese society in the 10th century to the first half of the sixteenth century has made literature a unique appearance. Confucianism on the way of recession had no longer played its role as a dominant thought. Meanwhile Buddhism and Taoism continued to expand their influence on social life at that time. Taoism's thoughts have penetrated literary works through dissatisfied poet writers and those of liberal spirit. This shows that the Taoism thought has elicited the inspiration not only of philosophy but also of art and literature.

\section{SOME REVIEWS}

Considering these aspects, Taoism has been being a part that has a close relationship with traditional Chinese culture, influences and dedicates little to no development in ancient Chinese culture. Therefore, Taoism research is an important way in studying Chinese traditional culture in particular and the traditional culture of many Taoist countries affected by Taoism.

Through the stories in ancient Vietnamese novels, it can be seen that these stories were often fabulous. "Reading Truyenkytan pha (New genealogy of fantasy short stories), everyone can easily see that the four stories that we translated and introduced were all fabulous and strange" (Diem, D. T., 1962 , p. 12).However, behind those stories were the social problems that were arising and were unable to practically solved, so they (a part of Vietnamese people) wanted to find an unworldly solution in the life of troubles and disasters.

The works revealed humans' desire to escape from the real world to find an ideal society on earth. This cynical point of view more or less showed the criticism of the authors in the context of a chaotic country full of uncertainties.

Through the legendary stories that were collected and recorded, we can see our ancestors' conception of national history, customs and habits, human behaviors, etc. and their selective reception of cultural values from other countries in the world (especially a large country like China). 


\section{CONCLUSION}

In the course of its development, although there was a time when Taoism was exploited by peasants, it became a spiritual support for the masses to fight against feudal forces, but in essence, there were also reflected the limited nature of human awareness in underdeveloped economic, scientific and technological periods. The ideal of immortal life, elves is an expression of the dream of a prosperous, happy life, different from the life of darkness, suffering and injustice. Although there are some negative existences, in the course of their existence and development, Taoism has also made significant contributions in many aspects of Chinese civilization.

To sum up, it can be said that Taoism contributed to stimulating the imagination of writers on their way to find the true, the good and the beautiful of life, making people become more and more perfect and enjoy more literacy sense of beauty. For the development of our country's literature, Taoism contributed to leading novels from Butky to Chichquai, Truyenky and some other genres like diem tinh, cong an, etc.

Today, although mythical stories are no longer valuable in modern life. However, what it brings in life is still valid. Research what has gone through to help us better understand the values of the present. The sources of life always flow from the past to the present

Receiving Taoism in its most positive aspects, Vietnamese authors in history created a leisurely tradition with the peaceful life in the countryside. In addition, for the national literature, they created a comfortable space in the strict, hasty and unfair society.

\section{REFERENCES}

[1] Can. N. D. (1992). General philosophy of Chinese philosophy: Trang Tủ essence. Vietnam: Ho Chi Minh.

[2] Chi. H. H. (1983). The faces of Vietnamese poetry (ancient and modern period). Hanoi: New work Vietnamese writers' association.

[3] Chinh. N. V. \& Mien. V. Q. (trans: Thu. L. D.) (1994). Outline the history of Chinese culture. Hanoi:Culture Information.

[4] Davidson, H. R. E. (1975). Folklore and literature. Folklore, 86, 73-93. Retrieved from http://www.jstor. org/stable/1259667

[5] Du, N. K.(Editor - 1963) (trans: Institute of Han Nom Studies, Vietnam).History of Chinese philosophy. China: Beijing.

[6] Du. N. K. (1990).Chinese Taoism history. Shanghai: people.

[7] Nguyen Du. TrucKhe, (trans: Literature Teaching Association of Ho Chi Minh City).(1998).Truyenky man luc.Ho Chi Minh City: Culture-Literature and Arts.

[8] Dai Viet Su KyToan Thu, "Noicacquan ban" edition; Wood edition was carved in the 18th year of ChinhHoa government 1697. Volume 1. Hanoi: Social Sciences.

[9] Dai Viet Su KyToan Thu, "Noicacquan ban" edition; Wood edition was carved in the 18th year of ChinhHoa government 1697. Volume 2. Hanoi: Social Sciences.

[10] Diem, D. T. (1962). (trans: Chi, N. L. \&Giap, T. V.).Truyenky tan pha. Hanoi: Education.

[11] Hanoi National University of Education, Center for Chinese Studies. (2000).Dao giaova van hoa. Hanoi: Culture and Information.

[12] Hinh, N. D. (2003). Vietnamese people with Taoism.Hanoi:Social Sciences.

[13] Hung. N. P. (2001). Vietnamese literature from the 10th century to the twentieth century. Vietnam: Hanoi National University.

[14] Huu, T. S.\& Can, T. H.(1990).Chinese fairytales. Shanghai: Literature \& Art.

[15] Huyen, N. V. (1995). Contributing to the study of Vietnamese culture, Volume 1. Hanoi: Social Sciences.

[16] Institute of scientific information. (1996). Folder Than tich, Than sac. Hanoi: Social Sciences.

[17] Khanh. D. G. (1983).Nguyen BinhKhiem's Poetry. Hanoi: Literature.

[18] Khanh. D. G., Tan. B. D. \& Chapter. M. C. (2002). Vietnamese literature: X century - first half of XVIII century. 6th edition. Hanoi: Education.

[19] Management board of relics and landscapes in Hanoi. (2000).Historical and cultural relics of Hanoi. Hanoi: National politic.

[20] Ngoc. N. M.(2000). Hanoi goddess. Vietnam: Ca Mau.

[21] Quynh. V. \&Phu. K. (trans: Khanh. D. G.\&San. N. N.) (2017).Linh Nam trichquai. Hanoi: Kim Dong. 
[22] Sam, H. P. (Editor-1995).Great dictionary of Chinese Taoism. Beijing: Social Sciences.

[23] Thanh Tong di thao. (trans: Ngo. N. B.)(2016).Gaigon: Nha Nam.

[24] Them. T. N. (2000).Vietnamese cultural establishment. Hanoi:. Education.

[25] Thompson, S. (1958). Motif-index of folk-literature: A classification of narrative elements in folktale, ballads, myths, fables, medieval, romances, exempla, and local legends (rev.ed). Bloomington: Indiana University Press.

[26] Tung thu tam bach de (History of Chinese Culture). (trans: Thuan. N., Dat. D. D.\&Chi. D. P.) (1999). Hanoi: Vietnam Culture and Information.

[27] Xun, L. (1959). A brief of Chinese fiction (trans: H. Y. Yang \& G. Yang). Beijing: Foreign Languages Press

[28] Xuyen, L. T. (trans: Muc. L. H.).Viet Dien U Linh. Retrieved from www.lichsuvietnam.info.

\section{AUTHOR'S BIOGRAPHY}

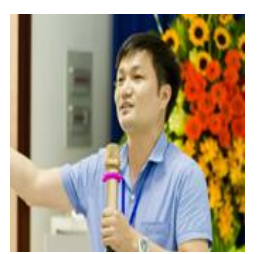

Dr. Vu Hong Van is Head of Basic Science in University of Transport and Communications. His field of study is Philosophy, Culture, Education science.

Citation: Vu Hong Van. "Identify the Imprints of Taoism in Vietnam's Ancient Literature”. International Journal of History and Cultural Studies (IJHCS). vol 5, no. 3, 2019, pp. 19-27 doi: DOI: http://dx.doi.org/lo. 20431/2454-7654.0503002.

Copyright: (C) 2019 Authors. This is an open-access article distributed under the terms of the Creative Commons Attribution License, which permits unrestricted use, distribution, and reproduction in any medium, provided the original author and source are credited. 